\title{
Prognostic assessment in IPF
}

\author{
Sara Tomassetti \\ Claudia Ravaglia \\ Carlo Gurioli \\ Giorgia Chiappalone \\ Venerino Poletti
}

Department of Diseases of the Thorax, GB Morgagni Hospital, Forlì (FC), Italy

Address for correspondence:

Sara Tomassetti, MD

Pulmonary Medicine Unit, Department of Diseases of the Thorax

GB Morgagni Hospital

Via C. Forlanini 34, 47100 Forlì (FC), Italy

Phone: +390543 735828 - Fax: +39 054360347

E-mail: s.tomassetti@gmail.com

\section{Summary}

Idiopathic pulmonary fibrosis (IPF) is a progressive and lethal form of fibrotic interstitial lung disease (ILDs). The clinical profile and natural history are extremely heterogeneous, some patients progress rapidly, while others slowly. A proportion of patients experience acute exacerbations of IPF, an accelerated lung function decline of unknown cause that to date is still unpredictable. Moreover the natural course of IPF is influenced by different comorbidities. The intrinsic complexity of this entity makes very challenging to find reliable and standardized methods of prognostic assessment. Multidimensional indices and staging systems have been recently proposed. The advantage of multidimensional indices is that they are more accurate in predicting IPF prognosis compared to single prognostic clinical factors. Currently both functional variables and multidimensional indices are used in clinical practice to discuss prognosis with patients and to guide both treatment and monitoring decisions. Despite these recent progresses we are still unable to predict the rate of disease progression, the risk of acute exacerbations and the most frequent and lethal comorbidities, such as pulmonary hypertension and lung cancer, that may swerve disease course. Future research in the field of genotyping and biomolecular profiling of this heterogeneous entity, will hopefully allow important steps on the complex pathway of IPF prognostic assessment.
KEY WORDS: interstitial lung diseases; idiopathic pulmonary fibrosis; staging system; prognostic factors; mortality.

The heterogeneous natural history of Idiopathic Pulmonary Fibrosis

Idiopathic pulmonary fibrosis (IPF) is a relentlessly progressive interstitial lung disease (ILD) leading to chronic respiratory failure and death. The survival rate is $2-3$ years (1). The functional evolution is heterogeneous, the majority of patients progresses slowly, whereas a minority (approximately $10 \%$ ) is subject to acute exacerbations of unknown cause, and others may experience sudden worsening caused by concomitant events such as embolism, respiratory infections/pneumonia, pneumothorax, heart failure, drug toxicity or surgical interventions (2-7).

Death is mainly related to the progression of the disease, leading to respiratory failure. Some other events such as lung cancer, heart failure, ischemic heart disease, pulmonary embolism, pneumothorax, respiratory infections can be also lethal in a minority of patients (8).

Natural history of IPF is influenced by different comorbidities, such as pulmonary hypertension, gastric reflux disease, respiratory diseases related to sleep, obesity, diabetes, heart disease, lung cancer and emphysema $(9,10)$. The consequences of each of these comorbidities on the natural history of IPF and its prognosis have not been fully clarified. Pulmonary hypertension (11) and lung cancer (12) have a documented negative prognostic impact on survival. However, today there are no approved treatment for pulmonary hypertension incidental to IPF, neither it is defined which could be the best therapeutic treatment for patients affected by lung cancer (12-14).

Obesity has been reported as a positive prognostic factor (15), while heart disease and diabetes mellitus are documented negative prognostic factors $(9,16)$. It is unclear whether the coexistence of emphysema influences IPF survival (17). Sleep disorders have a high prevalence in IPF, and may influence the quality of life (18). Gastroesophageal reflux disease may be 
related to both acute exacerbations and mortality (19) and an appropriate treatment of RGE is advisable (20).

Predictive factors are still unclear. Research is actively focused on identification of both clinical and biological factors influencing the natural history of IPF and its response to therapy.

\section{Clinical predictors of IPF prognosis}

Predicting IPF prognosis is of great clinical relevance and influence important clinical decisions concerning pharmacologic treatment, non-pharmacologic treatment and lung transplantation. Several single prognostic factors have been identified, and the most relevant for clinical practice, reported by the current ATS/ERS guidelines (1), are documented in Table 1. Multidimensional indices and staging systems have been recently proposed. The advantage of multidimensional indices is that they are more accurate in predicting IPF prognosis compared to single prognostic factors. Wells et al. (21), suggested the composite physiologic index (CPI) which uses FEV1, FVC and DLCO in order to predict the radiological extension of the fibrosis and its mortality. It is more accurate than both previous score clinicalradiological-functional and the use of its single variables. Recently some studies are suggesting the use of multidimensional indices that combine clinical parameters and biomarkers. The PCMI (Personal Clinical and Molecular Mortality Index, clinical-molecular death rate personalized) is a multidimensional index which combines the use of

Table 1 - GAP index, multidimensional index based on age, gender, FVC and DLCo\% of the predict (modified from 24). For each factor are assigned points (range 0-3) and then added up, total possible points range from 0 to 8 . Stages are stratified according to total points. Stages correlate with mortality (C-index 0,7$)$ and a scheme for follow-up is proposed accordingly. Patients who are unable to perform DLco due to the severity of respiratory function, are assigned to the category: "unable to perform". The GAP can't be calculated when DLco is not performed for other causes not related to respiratory dysfunction (i.e. technical difficulties).

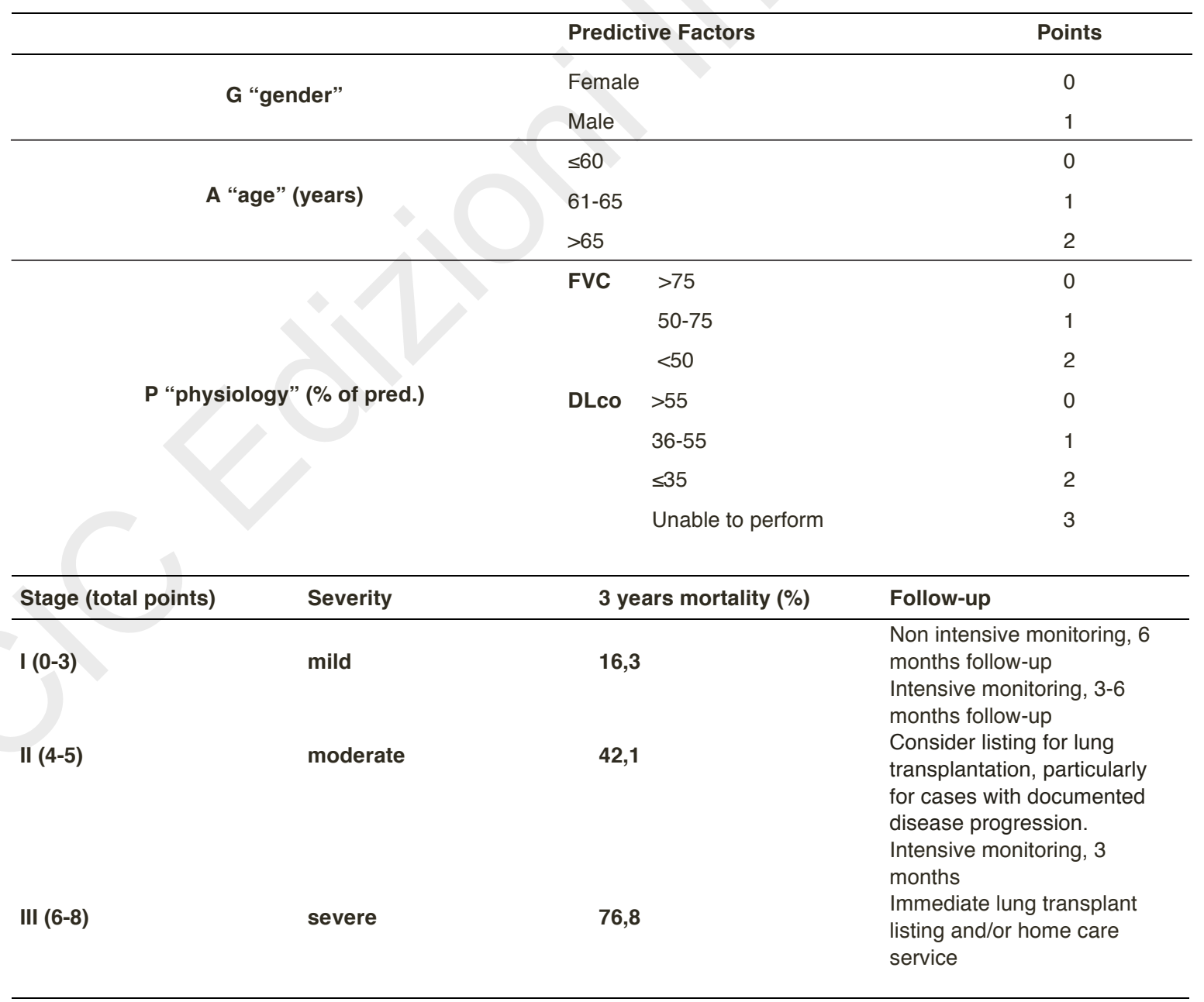


both clinical parameters and serum levels of MMP-7 (22). Patients with $\mathrm{PMCl}<330$ have an average survival rate of 5.13 years, those with $\mathrm{PCMI} \geq 330$ have a survival rate of 1.56 years. The attempt to create a score combined is surely innovative and of great interest. However, its use in clinical practice is not recommendable, as this research has some significant limits: its results have been only partially confirmed, it is not clear how much using MMP-7 could contribute, in predictive terms, to the use of clinical and physiological variables, and it lacks longitudinal data. Mura et al. (23) have derived from an Italian prospective cohort of 70 patients the Risk stratificatiOn ScorE (ROSE). The ROSE has also been validated in an Italian retrospective cohort of 68 patients. The three predictive factors of mortality identified are: (1) the severity of dyspnea measured by Medical Research Council Dyspnea Score (MRCDS) $>3$ (HR=6.77, $\mathrm{p}<0,0005)$; (2) the distance walked in the 6 minute walking test $\leq 72 \%$ pred $(\mathrm{HR}=3.27, \mathrm{p}<0.0162) ;$ (3) $\quad \mathrm{CPI}>41$ $(H R=5.36, p<0.0071)$. The score stratifies patients in three groups: high, medium and low risk of mortality at three years, which is respectively 19, 42 and $100 \%$ (sensitivity $=39 \%$ and specificity $=100 \%$ ). Ley et al. (24) identified a very simple staging system, GAP score (Gender, Age , Physiology) based on four clinical variables: (1) sex, (2) age, (3) FVC \% of pred. and (4) DLco \% of pred. This score was derived from an American retrospective cohort of 228 patients, and was validated in two external cohorts (one American and one Italian cohort of 447 total patients). The GAP staging system stratifies patients in three groups: I) mild with mortality in three years of $15,7 \%$, II) moderate with mortality of $35,7 \%$ and III) severe with mortality in three years of $66,2 \%$ [C-index $(95 \% \mathrm{Cl}) 69.5$ (65.6-62.7)]. The large cohort of patients studied, including also those unable to perform walking test or $\mathrm{DLco}$, is a clear advantage. This simple clinical tool could be useful in staging IPF guiding diagnostic and therapeutic decisions.

\section{Longitudinal monitoring}

Functional monitoring is meant to promptly identify those patients who progress rapidly. The longitudinal prognostic factors identified by international guidelines are: the aggravation of dyspnea, a reduction in FVC $\geq 10 \%$, a reduction in DLco $\geq 15 \%$ and a wider extension of fibrosis in TCHR. Heterogeneity of questionnaires used in different studies to quantify the grade of dyspnea, makes difficult to choose the best standardized method to asses dyspnea in IPF. Moreover, the dyspnea is anyway a parameter characterized by a limited reliability, due to his subjective intrinsic nature. Therefore disease progression (POD) is currently defined by the presence of one or more of the three longitudinal criteria previously mentioned (FVC, DLCo, TCHR worsening defines the progression of disease).

Among the physiological longitudinal factors, a decline of the forced vital capacity (FVC) of $5 \%$ or $10 \%$ of the theoretical, in absolute value, in 6 or 12 months has been demonstrated to be a solid negative prognostic factor $(25,26)$. Du Bois et al. (27) computed a multidimensional index which allows to predict the mortality due to IPF after 12 months, also using longitudinal predictive factors. A simplified model, which is as accurate as the global model, includes four variables (age, number of hospitalization, and variation of FVC and DLco in 24 weeks). Richeldi et al. (28) demonstrated the validity of using also the relative decline of $10 \%$ in FVC, which allows an identification of the progression of the disease in almost twice the number of patients compared to absolute decline of $10 \%$ (30 vs 18\%, $\mathrm{p}<0,0001)$. In clinical practice the progression should always be timely detected. Because of both possible fluctuating FVC values over time and biases related to low accuracy of real-life functional measurements, in order to define a progression of disease (POD), it is recommendable to confirm the functional deflection in at least two tests (4 weeks apart), or to document an evident radiological progression by HRCT.

Current international guidelines (1) do not establish the timing of follow-up, but suggest 3-6 months visits. Ley et al. (24) proposed a monitoring scheme based on IPF stage calculated by GAP index, consisting in a visit every six month for mild disease (stage I), and a close monitoring every 3 to 6 months I moderate disease (stage II). For patients with advanced disease (stage III) the patients should be immediately referred to transplant center or palliative care. These indications are meant to be discussed with the patient and tailored according to specific needs of each patient. GAP index calculation and indications for follow-up are summarized in Table 1.

Currently there is no consensus guideline suggesting the right approach to monitor IPF patients for possible complications of the disease, such as pulmonary hypertension, pulmonary embolism, lung cancer and coronary heart disease. It is unknown whether the screening and the prompt treatment of lung cancer could be of any clinical utility for these patients or not. HRCT should be performed not more frequently than every year, if not for specific indications. An annual HRCT might be reasonable to monitor disease course and also to screen patients for lung cancer in patients with mild-moderate IPF, and/or waiting for lung transplantation. However there is no clear evidence supporting this practical approach. Pulmonary hypertension could have negative prognostic implications, and it is quite important for patients waiting for lung transplantation. It is advisable to consider patients with echocardiography in diagnosis and in case of acute exacerbation, or progression of the disease, in order to estimate the derived pulmonary pressure. Consid- 
ering the risks, the use of right cardiac catheterization for an accurate valuation of pulmonary pressure is currently used in the pre-transplant screening or in clinical trials. To date there are no approved pharmacological therapies for pulmonary hypertension related to IPF.

\section{Acute exacerbations of IPF}

Accelerated phases, called also acute exacerbations of IPF (AE-IPF) are rapid and unpredictable deteriorations of lung function. The eti-

Due to the lack of
other prognostic indi-
ces which can be im-
mediately used in cli-
nical practice, the use
of THCR is of great
clinical utility.
ology is unknown. Among the risk factors for acute exacerbations, there are GERD, respiratory infections, and surgery, particularly surgical lung biopsy (29) and lobectomy (14). The onset respiratory failure is rapid (weeks or days), and the mortality is very high (about $78 \%)(5,7)$. Collard et al. (5) defined five diagnostic criteria of acute exacerbations in IPF. Acute exacerbations are characterized by a rapid (within 30 days) worsening dyspnea or of gas exchange (with a reduction of $\mathrm{PaO} 2 \geq 10$ $\mathrm{mmHg}$ ), and an HRCT documenting ground glass and/or consolidations superimposed to IPF pattern. Exclusion infections or other known causes of acute pulmonary damage like pulmonary embolism, cardiogenic shock or other causes of diffuse alveolar damage is always required. Clinically, cough and persistent low grade fever, preceding the onset of respiratory failure don't exclude the diagnosis of acute exacerbation (6) and this makes the clinical differential with infections very challenging. BAL (Broncho-Alveolar Lavage) is useful not only to exclude infections, but also to document cytophatological aspect compatible with diffuse alveolar damage. BAL cellularity usually shows neutrophilia (6). The BAL is advisable, but not always possible: risks and potential benefits must be accurately balanced in every single case, and when possible, discussed also with the patient. Research describing anatomopathological aspects of acute exacerbation are reported in literature. Diffuse alveolar damage superposed on UIP pattern is the most frequently reported, but pattern of organizing pneumonia (OP), capillaritis often associated to ANCA positivity have been also reported (5). The histopathological diagnosis is not required and, considering the risks, it is not advisable. Currently, a patognomonic biological marker of acute exacerbation of IPF has not been found. In peripheral blood different profiles have been described such as neutrophilia, increasing inflammation indices, increased KL-6 and LDH. The predictive value of these markers is to be defined in future studies. The HRCT is the key point of AE-IPF diagnosis, and a recent research described also its prognostic value. The valuation of extension and distribution of ground glass opacities in TCHR seems to have a prognostic value. Akira et al. (30) showed that distribution of superimposed ground glass opacity correlates with survival. Peripheral distribution, multifocal distribution and diffuse ground glass correlate with a median survival time of 540 days, 240 days and 16 days respectively. In expert centers this approach can be of a simple and immediate use. Due to the lack of other prognostic indices which can be immediately used in clinical practice, the use of THCR is of great clinical utility.

The treatment of AE-IPF is empirical and there are no randomized and controlled studies documenting the safety and/or efficacy of a specific therapy. A broadrange antibiotic treatment, associated with high doses of steroid (i.e. three days with intravenous methylprednisolone $125 \mathrm{mg}$, or $500 \mathrm{mg}$, or $1 \mathrm{~g}$ and then two days a $500 \mathrm{mg}$ ) is the most common approach to $A E$ IPF. Steroid treatment have to be modulated according to the severity of respiratory failure, age and general conditions of the patient. It is not recommendable the use of immunosuppressive drugs (cyclophosphamide or ciclosporin) in the majority of patients, and it is unadvisable in case of uncertain respiratory infection (for example, when there are clinical equivocal elements such as fever, productive cough, when it is not possible to perform a BAL). Oxygen therapy, in high fluxes too, is always suggested and it has to be modulated according to the seriousness of the hypoxemia. Invasive or non invasive mechanical ventilation in these patients has not reported satisfying results and the mortality in 30 days is very high $(78 \%)$ even using lung protective strategies of ventilation $(5,31)$. Ventilation is not recommendable in the majority of patients (32). Shared care pathway with hospice and palliative care units are always desirable, especially in reference centers.

\section{Conclusions}

In conclusion the heterogeneous profile of IPF and the numerous precipitating events that can occur, make the natural history of this disorder very difficult to be predicted. Currently clinical predictors of survival, particularly multidimensional systems, seem to be the most reliable prognostic assessment methods. Functional variables and multidimensional indices are used in clinical practice to discuss prognosis with patients and to guide both treatment and monitoring decisions. However we are unable to predict disease progression, acute exacerbations and the most frequent and lethal comorbidities, such as pulmonary hypertension and lung cancer,
However we are unable to predict disease progression, acute exacerbations and the most frequent and lethal comorbidities, such as pulmonary hypertension and lung cancer, that may swerve disease course. that may swerve disease course. Future research in the field of genotyping and biomolecular profiling of this heterogeneous entity, hopefully will allow impor- 
tant steps on the complex pathway of IPF prognostic assessment.

\section{Disclosure}

Conflict of Interest: S.T. and V.P. have received fees from Boehringer Ingelheim and Intermune, not related to this publication.

Sponsor: AMMP Associazione Morgagni Malattie Polmonari.

\section{References}

1. An Official ATS/ERS/JRS/ALAT Statement. Idiopathic pulmonary fibrosis: evidence-based guidelines for diagnosis and management. Am J Respir Crit Care Med. 2011;183:788-824.

2. Fernandez Perez ER, Daniels CE, Schroeder DR, St Sauver J, Hartman TE, Bartholmai BJ, et al. Incidence, prevalence, and clinical course of idiopathic pulmonary fibrosis: a population-based study. Chest. 2010;137:129-37.

3. Kim DS, Collard HR, King TE Jr. Classification and natural history of the idiopathic interstitial pneumonias. Proc Am Thorac Soc. 2006;3:285-92.

4. Martinez FJ, Safrin S, Weycker D, Starko KM, Bradford WZ, King TE Jr, et al., IPF Study Group. The clinical course of patients with idiopathic pulmonary fibrosis. Ann Intern Med. 2005;142:963-7.

5. Collard HR, Moore BB, Flaherty KR, Brown KK, Kaner RJ, King TE Jr, Lasky JA, Loyd JE, Noth I, OIman MA, et al.; Idiopathic Pulmonary Fibrosis Clinical Research Network Investigators. Acute exacerbations of idiopathic pulmonary fibrosis. Am J Respir Crit Care Med. 2007;176:636-643.

6. Ambrosini V, Cancellieri A, Chilosi M, Zompatori M, Trisolini R, Saragoni L, Poletti V. Acute exacerbation of idiopathic pulmonary fibrosis: report of a series. Eur Respir J. 2003;22:821-826.

7. Kim DS, Park JH, Park BK, Lee JS, Nicholson AG, Colby T. Acute exacerbation of idiopathic pulmonary fibrosis: frequency and clinical features. Eur Respir J. 2006;27:143-150.

8. Olson AL, Swigris JJ, Lezotte DC, Norris JM, Wilson CG, Brown KK. Mortality from pulmonary fibrosis increased in the United States from 1992 to 2003. Am J Respir Crit Care Med. 2007;176:277-284.

9. Hyldgaard C, Hilberg O, Bendstrup E. How does comorbidity influence survival in idiopathic pulmonary fibrosis? Respir Med. 2014 Feb 2 [Epub ahead of print].

10. King C, Nathan SD. Identification and treatment of comorbidities in idiopathic pulmonary fibrosis and other fibrotic lung diseases. Curr Opin Pulm Med. 2013;19:466-73.

11. Lettieri CJ, Nathan SD, Barnett SD, Ahmad S, Shorr AF. Prevalence and outcomes of pulmonary arterial hypertension in advanced idiopathic pulmonary fibrosis. Chest. 2006 Mar;129(3):746-52.

12. Tomassetti S, Gurioli C, Ryu J, Decker P, Ravaglia C, Tantalocco P, Buccioli M, Piciucchi S, Sverzellati N,
Dubini A, Gavelli G, Chilosi M, Poletti V. The impact of lung cancer on survival of Idiopathic Pulmonary Fibrosis. Chest. 2014 Aug 28 [Epub ahead of print].

13. Kumar P, Goldstraw P, Yamada K, et al. Pulmonary fibrosis and lung cancer: risk and benefit analysis of pulmonary resection. J Thorac Cardiovasc Surg. 2003;125:1321-7.

14. Watanabe N1, Taniguchi $\mathrm{H}$, Kondoh $\mathrm{Y}$, Kimura $\mathrm{T}$, Kataoka K, Nishiyama O, Kondo M, Hasegawa Y.Alakhras M, Decker PA, Nadrous HF, CollazoClavell M, Ryu JH. Chemotherapy for extensivestage small-cell lung cancer with idiopathic pulmonary fibrosis. Int J Clin Oncol. 2013 April [Epub ahead of print].

15. Alakhras M, Decker PA, Nadrous HF, Collazo-Clavell $\mathrm{M}, \mathrm{Ryu} \mathrm{JH}$. Body mass index and mortality in patients with idiopathic pulmonary fibrosis. Chest. 2007 May;131(5):1448-53.

16. Nathan SD, Basavaraj A, Reichner C, Shlobin OA, Ahmad S, Kiernan J, Burton N, Barnett SD. Prevalence and impact of coronary artery disease in idiopathic pulmonary fibrosis. Respir Med. 2010 Jul;104(7):1035-41.

17. Ryerson CJ, Hartman T, Elicker BM, Ley B, Lee JS, Abbritti M, Jones KD, King TE Jr, Ryu J, Collard HR. Clinical features and outcomes in combined pulmonary fibrosis and emphysema in idiopathic pulmonary fibrosis. Chest. 2013 Jul;144(1):234-40.

18. Mermigkis $C$, Stagaki E, Tryfon S, Schiza S, Amfilochiou A, Polychronopoulos V, Panagou P, Galanis N, Kallianos A, Mermigkis D, Kopanakis A, Varouchakis G, Kapsimalis F, Bouros D. How common is sleepdisordered breathing in patients with idiopathic pulmonary fibrosis? Sleep Breath. 2010 Dec;14(4):38790.

19. Tcherakian C, Cottin V, Brillet PY, Freynet O, Naggara N, Carton Z, Cordier JF, Brauner M, Valeyre D, Nunes H.Lee JS, Ryu JH, Elicker BM, Lydell CP, Jones KD, Wolters PJ, King TE Jr, Collard HR. Progression of idiopathic pulmonary fibrosis: lessons from asymmetrical disease. Thorax. 2011 Mar;66(3): 226-31.

20. Gastroesophageal reflux therapy is associated with longer survival in patients with idiopathic pulmonary fibrosis. Am J Respir Crit Care Med. 2011 Dec 15;184(12):1390-4.

21. Wells AU, Desai SR, Rubens MB, Goh NS, Cramer $D$, Nicholson AG, et al. Idiopathic pulmonary fibrosis: a composite physiologic index derived from disease extent observed by computed tomography. Am J Respir Crit Care Med. 2003;167:962-9.

22. Richards TJ, Kaminski N, Baribaud F, Flavin S, Brodmerkel C, Horowitz D, Li K, Choi J, Vuga LJ, Lindell KO, Klesen M, Zhang Y, Gibson KF. Peripheral blood proteins predict mortality in idiopathic pulmonary fibrosis. Am J Respir Crit Care Med. 2012 Jan 1;185(1):67-76.

23. Mura M, Porretta MA, Bargagli E, Sergiacomi G, Zompatori M, Sverzellati N, Taglieri A, Mezzasalma F, Rottoli P, Saltini C, Rogliani P. Predicting survival in newly diagnosed idiopathic pulmonary fibrosis: a 3-year prospective study. Eur Respir J. 2012 Jul;40 
(1):101-9.

24. Ley B, Ryerson CJ, Vittinghoff E, Ryu JH, Tomassetti S, Lee JS, Poletti V, Buccioli M, Elicker BM, Jones KD, King TE Jr, Collard HR. A multidimensional index and staging system for idiopathic pulmonary fibrosis. Ann Intern Med. 2012 May 15;156(10):684-91.

25. Egan JJ, Martinez FJ, Wells AU, Williams T. Lung function estimates in idiopathic pulmonary fibrosis: the potential for a simple classification. Thorax. 2005;60:270-273.

26. Latsi PI, du Bois RM, Nicholson AG, Colby TV, Bisirtzoglou D, Nikolakopoulou A, Veeraraghavan S, Hansell DM, Wells AU. Fibrotic idiopathic interstitial pneumonia: the prognostic value of longitudinal functional trends. Am J Respir Crit Care Med. 2003;168: 531-537.

27. du Bois RM, Weycker D, Albera C, Bradford WZ, Costabel U, Kartashov A, et al. Ascertainment of individual risk of mortality for patients with idiopathic pulmonary fibrosis. Am J Respir Crit Care Med. 2011;184:459-66.
28. Richeldi L, Ryerson CJ, Lee JS, Wolters PJ, Koth LL, Ley B, Elicker BM, Jones KD, King TE Jr, Ryu JH, Collard HR. Relative versus absolute change in forced vital capacity in idiopathic pulmonary fibrosis. Thorax. 2012 May;67(5):407-11.

29. Utz JP, Ryu JH, Douglas WW, Hartman TE, Tazelaar HD, Myers JL, et al. High short-term mortality following lung biopsy for usual interstitial pneumonia. Eur Respir J. 2001;17:175-9.

30. Akira M, KozukaA, Yamamoto S, Sakatani M, et al. Computed Tomography Findings in Acute Exacerbation of Idiopathic Pulmonary Fibrosis. Am J Respir Crit Care Med. 2008 Aug 15;178(4):372-8.

31. Gaudry S, Vincent F, Rabbat A, Nunes H, Crestani B, Naccache JM, Wolff M, Thabut G, Valeyre D, Cohen $\mathrm{Y}$, Mal H. Invasive mechanical ventilation in patients with fibrosing interstitial pneumonia. J Thorac Cardiovasc Surg. 2014 Jan;147(1):47-53.

32. Mallick S. Outcome of patients with idiopathic pulmonary fibrosis (IPF) ventilated in intensive care unit. Respiratory Medicine. 2008;102:1355-1359. 